\title{
Urban aerosol size distributions over the Mediterranean city of Barcelona, NE Spain
}

\author{
M. Dall'Osto ${ }^{1}$, D.C.S. Beddows ${ }^{2}$, J. Pey ${ }^{1}$, S. Rodriguez ${ }^{3,}{ }^{*}$, A. Alastuey ${ }^{1}$, Roy M. Harrison ${ }^{2, * *}$, and X. Querol ${ }^{1}$ \\ ${ }^{1}$ Institute for Environmental Assessment and Water Research (IDǼA-CSIC), Barcelona, Spain \\ ${ }^{2}$ National Centre for Atmospheric Science, School of Geography, Earth and Environmental Sciences University of \\ Birmingham, Edgbaston Birmingham B15 2TT, UK \\ ${ }^{3}$ University of Huelva (Spain) at the Izana Atmospheric Observatory, INM-CSIC, La Marina 20, 6a planta, 38071, Santa Cruz \\ de Tenerife, Canary Islands, Spain \\ * currently at: Izaña Atmospheric Research Centre, AEMET, Joint Research Unit to CSIC "Studies on Atmospheric \\ Pollution", La Marina 20, Planta 6, 38071 Santa Cruz de Tenerife, Canary Islands, Spain \\ **also at: Centre of Excellence in Environmental Studies, King Abdulaziz University, P.O. Box 80203, Jeddah (21589), \\ Saudi Arabia
}

Correspondence to: M. Dall'Osto (manuel.dallosto@gmail.com)

Received: 1 June 2012 - Published in Atmos. Chem. Phys. Discuss.: 4 July 2012

Revised: 6 November 2012 - Accepted: 7 November 2012 - Published: 16 November 2012

\begin{abstract}
Differential mobility particle sizer (DMPS) aerosol concentrations $\left(\mathrm{N}_{13-800}\right)$ were collected over a oneyear-period (2004) at an urban background site in Barcelona, North-Eastern Spain. Quantitative contributions to particle number concentrations of the nucleation (33-39\%), Aitken $(39-49 \%)$ and accumulation mode $(18-22 \%)$ were estimated. We examined the source and time variability of atmospheric aerosol particles by using both K-means clustering and Positive Matrix Factorization (PMF) analysis. Performing clustering analysis on hourly size distributions, nine K-means DMPS clusters were identified and, by directional association, diurnal variation and relationship to meteorological and pollution variables, four typical aerosol size distribution scenarios were identified: traffic (69\% of the time), dilution ( $15 \%$ of the time), summer background conditions ( $4 \%$ of the time) and regional pollution (12\% of the time). According to the results of PMF, vehicle exhausts are estimated to contribute at least to $62-66 \%$ of the total particle number concentration, with a slightly higher proportion distributed towards the nucleation mode (34\%) relative to the Aitken mode (28-32\%). Photochemically induced nucleation particles make only a small contribution to the total particle number concentration (2-3\% of the total), although only particles larger than $13 \mathrm{~nm}$ were considered in this study. Overall the combination of the two statistical methods is successful
\end{abstract}

at separating components and quantifying relative contributions to the particle number population.

\section{Introduction}

Urban air pollution is one of the environmental problems of major concern and, due to growing urbanization, will probably become increasingly important in the future. The quality of air we breathe is typically expressed in terms of a number of air pollutants that have adverse effects on human health and the environment. Those pollutants include gaseous pollutants such as ozone, nitrogen dioxide, carbon monoxide, sulphur dioxide as well as airborne particulate matter, expressed as mass and number concentration. Legally required routine monitoring of key urban pollutants is widely performed (EEA 2009). However, at present there are no air quality standards for particle number concentrations in ambient air although some European countries have local observation networks (Reche et al., 2011).

Particulate matter is one of the key urban pollutants and much research has focused on the smaller size fractions. Ultrafine particles (UF) are defined as those with diameters smaller than $0.1 \mu \mathrm{m}(100 \mathrm{~nm})$, they make the highest contribution to the total particle number concentrations, but only a 
small contribution to particle volume or mass (Harrison et al., 2000a, b). It is widely accepted that exposure to air pollutants may have severe consequences for human health, including diseases of the respiratory and cardiac systems (Atkinson et al., 2010; Pope et al., 2002). Toxicological studies have suggested that UF are more toxic than coarser particles, per unit mass (Davidson et al., 2005; Seaton et al., 1995). The UF variability in urban environments is largely determined by local emission sources and atmospheric processes (Reche et al., 2011). Aerosol number size distributions in the urban area are mainly a function of a number of factors, including primary emissions (i.e. traffic, industrial and domestic emissions), meteorological factors, and long-range transport from diverse sources and regions (Hussein et al., 2006; Yue, 2009; Costabile et al., 2009). In the Helsinki urban area the temporal variation of the particle number concentration showed close correlations with traffic activities (Hussein et al., 2004). Particle formation events (secondary particles governed from gas-to-particle conversion) can occur on a large regional scale (Kulmala et al. 2004); and have been observed impacting also major urban areas, favored during intense solar irradiance and in less polluted cooler drier air (Alam et al., 2003; Stanier et al., 2004; Wehner et al., 2007). Such events were found to present higher particle number concentrations at urban background sites relative to more urban downtown site in a major city, despite its high traffic density (Jeong et al., 2010).

It is therefore important to measure the complete aerosol size distribution in order to gain a better understanding of the source attribution of particles in the urban atmosphere (Harrison et al., 2011). Long-term and continuous aerosol particle number size distribution measurements are available for background sites (Asmi et al., 2011) but they are still scarce in urban areas. In this study we utilize a long-term data set of aerosol particle number size distributions (13-800 nm) in the urban background air of Barcelona, a metropolis located in North Eastern Spain in the Western Mediterranean Basin (WMB) during the year 2004. Previous research (Pey et al., 2009) conducted in the study area identified five major emission sources (vehicle exhausts, mineral dust, sea spray, industrial source and fuel-oil combustion) and two atmospheric processes (photochemical induced nucleation and regional/urban background particles derived from coagulation and condensation processes) having influence on sizeselected particle number concentrations.

The objective of this work is to analyse different types of aerosol size distributions collected over a whole year of measurements and to apportion to sources. The peculiarity lies in the methods used for analyzing this long term urban aerosol size distribution dataset. All measured particle size distributions are considered (after quality assurance), and not filtered according to any other criteria. Different states of the aerosol are determined by using a novel application of K-means cluster analysis, which uses the degree of similarity and difference between individual observations to define the groups and to assign group memberships (Beddows et al., 2009). Additionally, continuous aerosol size distributions are also analyzed by using PMF (Harrison et al., 2011) which extracts component parts from a size distribution. Clustered data are used to study the large variations in size distributions, both spatially and temporally within a Mediterranean urban background location. Aerosol emission, formation, and dynamic processes are inferred from the K-means cluster characteristics and correlations with concurrently measured meteorological, gas phase, and particle phase measurements. Whilst a K-means cluster represents a full size distribution, a PMF factor represents only part of it. Consequently, a K-means cluster represents a typical aerosol size distribution at a given time, whereas a PMF factor is more related to a specific source or process. In other words, PMF can separate contributions to the size distribution of airborne particulate matter, whereas K-means clustering can describe the possible different combinations of particle size distributions occurring in the urban air studied. In this study, we apply these two powerful techniques to elucidate the influences upon measured size distributions.

\section{Methodology}

\subsection{Location}

The WMB region is influenced by peculiar atmospheric dynamics related to mesoscale and local/regional meteorological processes (Millán et al., 1997). There is an intense seasonal contrast concerning temperature, humidity and rainfall causing marked seasonal patterns for specific pollutants. Barcelona is the fifth most populous city in Europe, with about 1.7 million inhabitants in the city and around 3.5 millions in the metropolitan area. The urban design and activity around Barcelona account for the highest road traffic density of Europe (6100 cars $/ \mathrm{km}^{2}$, much more than in most European cities with 1000-1500 cars $/ \mathrm{km}^{2}$ ). Furthermore, Barcelona has one of the main harbours in the Mediterranean Basin, with the highest number of cruise ships for tourists in Spain, being a significant focus of emissions of atmospheric pollutants. In addition to the local Particulate Matter (PM) emissions, Saharan dust outbreaks reach the Barcelona area in the order of 7-10 events per year, with a major frequency in the summer and winter-spring periods (Rodriguez et al., 2001). Aerosol size distribution measurements were taken in the south west part of Barcelona, on the roof terrace ( $8 \mathrm{~m}$ above ground, about $50 \mathrm{~m}$ a.s.1.) of the Institute of Earth Sciences "Jaume Almera" (Consejo Superior de Investigaciones Cientificas: JA-CSIC) (Fig. 1). This is an urban background monitoring site influenced at times by heavy road traffic emissions from a major road (Diagonal Avenue, 132000 vehicles/day). This road is situated about $200 \mathrm{~m}$ North of the monitoring site, cutting the city of Barcelona from North East to south west (Fig. 1). This site was $200 \mathrm{~m}$ away from 


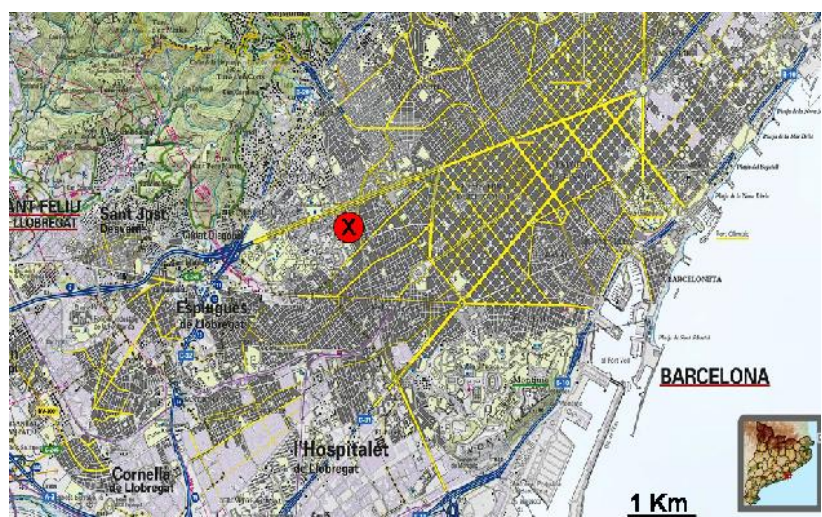

Fig. 1. Map of the studies: X. Institute of Earth Sciences "Jaume Almera", CSIC

the Urban Background site (UB) used during the SAPUSS project (Dall'Osto et al., 2012a)

\subsection{Differential Mobility Particle Sizer (DMPS)}

The DMPS data collected over the whole year 2004 were obtained by using a Condensation Particle Counter (CPC) TSI 3022 connected to a Differential Mobility Analyzer (DMA) TSI 3071. This equipment provided a complete size distribution of the number of particles between 13 and $800 \mathrm{~nm}$ (seven minutes resolution) using a software programmed at the European Union Joint Research Centre (EU-JRC-Ispra, Italy). The close loop sheath air used in the DMA was dried with silica gel before the zero particle filter (Pey et al., 2009).

\subsection{Concentrations of gaseous pollutants}

Gaseous pollutant data were not collected at the sampling site. However, the Department of the Environment for the Autonomous Government of Catalonia currently manages thirty one air quality monitoring station, three of which are classified as urban background ones (Sants, Ciutadella and Gornal-L'Hospitalet). A detailed analysis of the levels of gaseous pollutants $\left(\mathrm{NO}, \mathrm{NO}_{2}, \mathrm{CO}, \mathrm{O}_{3}\right.$ and $\mathrm{SO}_{2}$ ) of the three stations during the 2004 year gave similar trends, supporting the common "urban background" sampling site classification. Whilst the optimal arrangement would have been to measure gaseous pollutants at the monitoring site, for this study (like the ones of Pey et al., 2008; Pey et al., 2009) we make the approximation of considering our monitoring site similar to the air quality urban background monitoring stations, hence we use complementary data from the closest one (Gornal-L'Hospitalet, $3 \mathrm{~km}$ ). Local pollution from the Diagonal Avenue may at times impact the JA-CSIC monitoring site; although previous studies did not show major differences from the background sites, indicating that our JA-CSIC sampling site reflects the urban background atmosphere of
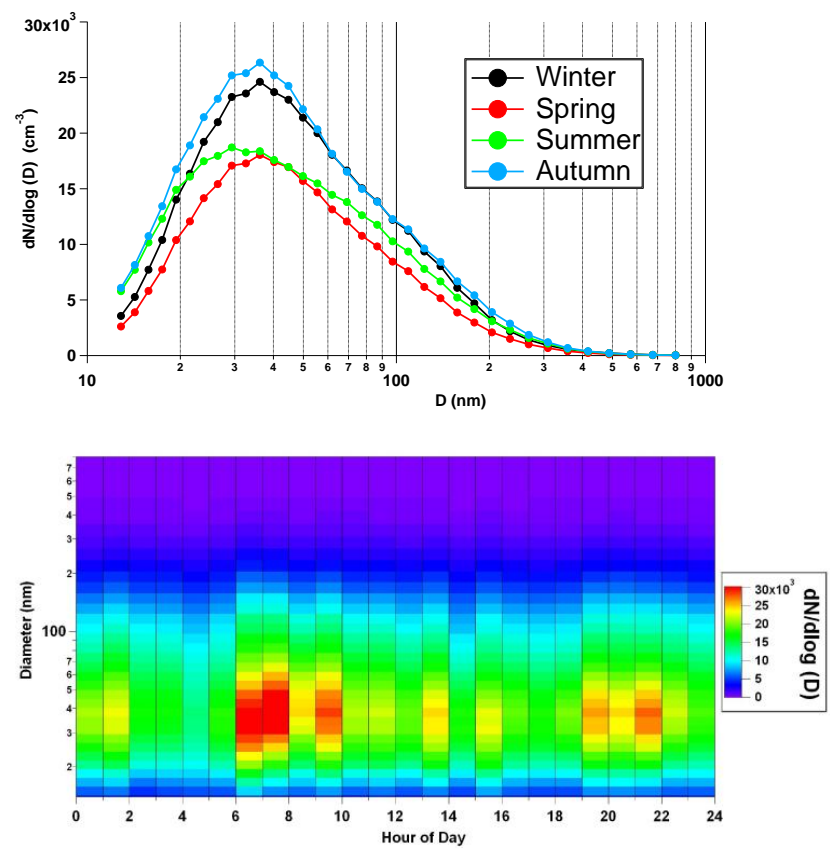

Fig. 2. (a). Average DMPS size distributions $\left(d \mathrm{~N} / d \log (D)-\mathrm{cm}^{-3}\right)$ for different seasons for the year 2004 (b). Diurnal profile (local time) of the DMPS size distributions $\left(d \mathrm{~N} / d \log (D)-\mathrm{cm}^{-3}\right)$.

Barcelona (Querol et al. 2001; Querol et al., 2004; Perez et al., 2008).

\subsection{Particulate Matter mass}

Simultaneously, levels of $\mathrm{PM}_{10}, \mathrm{PM}_{2.5}$ and $\mathrm{PM}_{1}$ were obtained at the monitoring over the same collection period, using an optical counter GRIMM 1108 which recorded PM levels on an hourly basis (Pey et al., 2008; Pey et al., 2009). The optical counter data were calibrated by comparison with simultaneous gravimetric measurements by using high volume samplers MCV-CAV $\left(30 \mathrm{~m}^{3} \mathrm{~h}^{-1}\right)$ with other $\mathrm{PM}_{\mathrm{x}}$ inlets (at least two $\mathrm{PM}_{10}$ two $\mathrm{PM}_{2.5}$ and two $\mathrm{PM}_{1}$ 24-h samples were collected every week), in accordance with guidelines EC (2001).

\subsection{Meteorological data}

Meteorological variables (atmospheric pressure, wind components, solar radiation, temperature and relative humidity) were obtained from a nearby meteorological station $(100 \mathrm{~m}$ distant from our measurement site) located on the roof terrace of the Chemical and Physical Sciences Faculty of the Barcelona University (UB). Moreover, data from the Fabra observatory (an astronomical and meteorological observatory located in Barcelona, located towards the south at $415 \mathrm{~m}$ altitude above sea level, at about $8 \mathrm{~km}$ from the monitoring site) were also used to complement the UB meteorological station data. 
Table 1. Data coverage of DMPS aerosol distributions during the year 2004 .

\begin{tabular}{ll}
\hline Month & $\begin{array}{l}\text { DMPS Data } \\
\text { coverage (\%) }\end{array}$ \\
\hline January & 20 \\
February & 73 \\
March & 68 \\
April & 84 \\
May & 62 \\
June & 1 \\
July & 81 \\
August & 76 \\
September & 88 \\
October & 87 \\
November & 78 \\
December & 26 \\
\hline
\end{tabular}

\subsection{Air mass back trajectories}

Back trajectories of the air masses arriving at Barcelona were calculated at midday (12:00) for each day of the campaign, depicting the path taken by the air mass reaching the sampling site over the previous five days. The back trajectories were run using the on-line HYSPLIT model developed by the National Oceanic and Atmospheric Administration (NOAA) (Draxler, 2003). Six different air mass scenarios were classified for this study: Atlantic North (ATL. N), Atlantic West (ATL. W), North African (NAF), European-Mediterranean (EUR-MED), Regional during summer times (REG SUM) and Regional during winter times (REG WIN) (Pey et al., 2008).

\subsection{Aerosol size distribution statistical analysis}

DMPS data were averaged in hourly bins for the analysis.

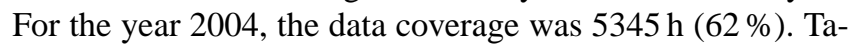
ble 1 shows the DMPS availability for each month of the year, with the months January, June and December scarcely represented.

\subsubsection{K-means clustering}

The hourly DMPS size distributions were subsequently normalised by their vector-length and cluster analysed (Beddows et al., 2009). The choice of K-means clustering was made from a selection of the partitional cluster packages (Beddows et al., 2009). The mathematical details of the method presented are available elsewhere (Beddows et al., 2009; Dall'Osto et al., 2011a). Briefly, K-means method aims to minimize the sum of squared distances between all points and the cluster centre. In order to choose the optimum number of clusters the Dunn-Index (DI) was used, which aims to identify dense and well-separated clusters. DI is defined as the ratio between the minimal intercluster distance to maxi- mal intra-cluster distance. In other words, for Dunn's index we wanted to find the clustering which maximizes this index. The use of cluster analysis was justified in this work using a Cluster Tendency test, providing a calculated a Hopkins Index of 0.20 and implying the presence of structures in the form of cluster in a dataset (Beddows et al., 2009). The Dunn-Index for the results of the K-means analysis for different cluster numbers showed a clear maximum for 14 clusters. However, by carefully looking at the clusters, these were reduced to 9 as the difference among some of them was minimal. It is important to note that the different aerosol size distribution clusters were merged not only upon their similar size distributions among each other but also by considering strong correlations with other physical and chemical parameters obtained with other instruments (Beddows et al., 2009; Dall'Osto et al., 2011a). One advantage of this clustering method over providing an average of aerosol size distributions is that it does provide a specific number of size distributions which can be compared across different time periods (Beddows et al., 2009). Some other examples of particle size distribution cluster analysis for substantial DMPS datasets can be found in the literature (Tunved et al., 2004; Charron et al., 2007; Costabile et al. 2009).

\subsubsection{PMF}

Continuous size distributions were also analyzed using Positive Matrix Factorization (Harrison et al., 2011). Using a PC running Windows XP with 4GB of RAM available, only 5000 can be cluster analysed at a time and many datasets exceed this limit. To address this problem, 5000 spectra are randomly selected from the dataset and used in the cluster analysis. The cluster result is then used to train a supervised learning technique (Support Vector Machine SVM - Dimitriadou et al., 2011) which is then used to classify the remaining spectra.

\section{Results}

Figure $2 \mathrm{a}$ shows the average size distributions for the four seasons of 2004, showing higher total particle number concentrations at all aerosol sizes from $13 \mathrm{~nm}$ to $800 \mathrm{~nm}$ during the colder months. Pey et al. (2008) have already shown that the aerosol number and mass concentrations can be affected by different sources and atmospheric processes. Figure $2 b$ represents the DMPS diurnal temporal profiles for all year 2004, showing a spike of UF particles during traffic rush hours in the morning (06:00-09:00 LT) and in the evening hours (20:00-22:00 LT). A less distinct enhancement is also seen in the afternoon, likely to be due to the photochemical nucleation events occurring during summer time (Rodríguez et al., 2007; Pey et al., 2008; Reche et al., 2011), although the long seasonally averaging time does not allow to clearly resolve it. Hence, in order to fully elucidate the chemical and 
Table 2. Average values associated to each of the nine DMPS clusters. Bold text are for particularly low and-or high values.

\begin{tabular}{|c|c|c|c|c|c|c|c|c|c|}
\hline \multirow{2}{*}{$\begin{array}{l}\text { Cluster type } \\
\text { Cluster number }\end{array}$} & \multicolumn{2}{|c|}{ Dilution } & \multicolumn{3}{|c|}{ Traffic } & \multicolumn{2}{|c|}{ Photochemical } & \multicolumn{2}{|c|}{ Regional } \\
\hline & 1 & 2 & 3 & 4 & 5 & 6 & 8 & 7 & 9 \\
\hline$\%$ of each cluster & 8 & 4 & 16 & 26 & 27 & 2 & 10 & 2 & 5 \\
\hline $\mathrm{N}_{13-100}\left(\mathrm{~cm}^{-3}\right)$ & $8.2 \times 10^{3}$ & $8.4 \times 10^{3}$ & $1.3 \times 10^{4}$ & $3.5 \times 10^{4}$ & $1.9 \times 10^{4}$ & $5.7 \times 10^{3}$ & $3.7 \times 10^{3}$ & 1.1.E+04 & $8.6 \times 10^{3}$ \\
\hline $\mathrm{N}_{100-800}\left(\mathrm{~cm}^{-3}\right)$ & $7.7 \times 10^{-2}$ & $8.7 \times 10^{-2}$ & $2.1 \times 10^{3}$ & $4.3 \times 10^{3}$ & $2.7 \times 10^{3}$ & $9.9 \times 10^{2}$ & $9.8 \times 10^{2}$ & $3.0 \times 10^{3}$ & $1.6 \times 10^{3}$ \\
\hline $\mathrm{N}_{13-800}\left(\mathrm{~cm}^{-3}\right)$ & $8.9 \times 10^{3}$ & $9.3 \times 10^{3}$ & $1.5 \times 10^{4}$ & $3.9 \times 10^{4}$ & $2.1 \times 10^{4}$ & $6.7 \times 10^{3}$ & $4.7 \times 10^{3}$ & $1.4 \times 10^{4}$ & $1.0 \times 10^{4}$ \\
\hline $\mathbf{S O}_{2}\left(\mu \mathrm{g} \mathrm{m}^{-3}\right)$ & $2.5 \pm 2.3$ & $1.7 \pm 1.5$ & $2.4 \pm 3.6$ & $4.2 \pm 4.1$ & $3.0 \pm 3.2$ & $1.5 \pm 1.6$ & $1.4 \pm 1.2$ & $4.7 \pm 7.4$ & $5.6 \pm 5.7$ \\
\hline $\mathrm{NO}\left(\mu \mathrm{g} \mathrm{m}^{-3}\right)$ & $15 \pm 21$ & $11 \pm 16$ & $15 \pm 16$ & $36 \pm 49$ & $26 \pm 32$ & $6 \pm 5$ & $10 \pm 21$ & $32 \pm 35$ & $47 \pm 71$ \\
\hline $\mathrm{NO}_{2}\left(\mu \mathrm{g} \mathrm{m}^{-3}\right)$ & $30 \pm 18$ & $25 \pm 21$ & $25 \pm 17$ & $42 \pm 25$ & $37 \pm 21$ & $13 \pm 8$ & $12 \pm 10$ & $34 \pm 26$ & $39 \pm 31$ \\
\hline $\mathbf{N O}_{\mathbf{x}}\left(\mu \mathrm{g} \mathrm{m}^{-3}\right)$ & $53 \pm 30$ & $41 \pm 30$ & $48 \pm 25$ & $97 \pm 40$ & $76 \pm 40$ & $22 \pm 15$ & $27 \pm 10$ & $83 \pm 30$ & $111 \pm 40$ \\
\hline$O_{3}\left(\mu \mathrm{g} \mathrm{m}^{-3}\right)$ & $35 \pm 20$ & $46 \pm 22$ & $47 \pm 26$ & $29 \pm 24$ & $30 \pm 20$ & $73 \pm 27$ & $66 \pm 29$ & $38 \pm 31$ & $40 \pm 20$ \\
\hline $\mathrm{CO}\left(\mathrm{mg} \mathrm{m}^{-3}\right)$ & $0.4 \pm 0.2$ & $0.4 \pm 0.2$ & $0.4 \pm 0.2$ & $0.6 \pm 0.4$ & $0.5 \pm 0.2$ & $0.3 \pm 0.2$ & $0.3 \pm 0.2$ & $0.5 \pm 0.4$ & $0.6 \pm 0.4$ \\
\hline $\mathbf{P M}_{1}\left(\boldsymbol{\mu} \mathbf{g ~ m}^{-3}\right)$ & $14 \pm 8$ & $15 \pm 8$ & $19 \pm 11$ & $20 \pm 12$ & $22 \pm 12$ & $18 \pm 6$ & $16 \pm 9$ & $32 \pm 18$ & $24 \pm 14$ \\
\hline $\mathbf{P M}_{2.5}\left(\mu \mathrm{g} \mathrm{m}^{-3}\right)$ & $18 \pm 10$ & $19 \pm 10$ & $23 \pm 12$ & $24 \pm 15$ & $27 \pm 15$ & $22 \pm 7$ & $20 \pm 11$ & $38 \pm 21$ & $28 \pm 11$ \\
\hline $\mathbf{P M}_{10}\left(\mu \mathrm{g} \mathrm{m}^{-3}\right)$ & $32 \pm 21$ & $\mathbf{3 3} \pm \mathbf{1 7}$ & $37 \pm 22$ & $40 \pm 27$ & $41 \pm 24$ & $35 \pm 11$ & $34 \pm 23$ & $\mathbf{5 2} \pm \mathbf{3 0}$ & $44 \pm 33$ \\
\hline $\operatorname{Temp}\left({ }^{\circ}\right)$ & $16.1 \pm 7$ & $21.2 \pm 7$ & $19.9 \pm 6$ & $15.9 \pm 5$ & $16.9 \pm 5$ & $27.2 \pm 6$ & $24.1 \pm 6$ & $17.0 \pm 5$ & $19.9 \pm 6$ \\
\hline $\mathbf{R H}(\%)$ & $61 \pm 18$ & $58 \pm 18$ & $68 \pm 16$ & $66 \pm 14$ & $70 \pm 15$ & $62 \pm 12$ & $68 \pm 12$ & $70 \pm 16$ & $68 \pm 13$ \\
\hline Pressure $(\mathbf{m b})$ & $1002.4 \pm 59$ & $1003.6 \pm 60$ & $1006.0 \pm 50$ & $1005.2 \pm 40$ & $1006.4 \pm 30$ & $1006.3 \pm 60$ & $1006.6 \pm 90$ & $1009.9 \pm 80$ & $1007.5 \pm 60$ \\
\hline W.S. U.B. $\left(\mathrm{m} \mathrm{s}^{-1}\right)$ & $2.7 \pm 1.5$ & $2.4 \pm 1.9$ & $2.2 \pm 1.5$ & $1.9 \pm 1.3$ & $2.0 \pm 1.5$ & $1.9 \pm 0.7$ & $2.1 \pm 1.3$ & $1.9 \pm 1.3$ & $1.8 \pm 1$ \\
\hline Radiation $\left(\mathbf{W} \mathbf{m}^{-2}\right)$ & $166 \pm 248$ & $284 \pm 301$ & $208 \pm 273$ & $136 \pm 222$ & $145 \pm 224$ & $487 \pm 308$ & $322 \pm 308$ & $167 \pm 257$ & $232 \pm 272$ \\
\hline
\end{tabular}

Table 3. Occurrence (\%) of different air mass types for each of the nine DMPS cluster. Air mass classification types: Atlantic North (ATL. N), Atlantic West (ATL. W), North African (NAF), European-Mediterranean (EUR-MED), Regional during summer times (REG. SUM.) and Regional during winter times (REG. WIN.) Bold text are for particularly low and-or high values.

\begin{tabular}{llllllll}
\hline \multicolumn{1}{c}{ Cluster } & \multicolumn{6}{c}{ Air mass back trajectories type } \\
\hline \multirow{2}{*}{ Dilution } & 1 & 39 & 25 & 14 & 8 & 11 & 2 \\
& 2 & 18 & 29 & 25 & 10 & 16 & 1 \\
\hline Traffic & 3 & 21 & 21 & 28 & 10 & 17 & 3 \\
& 4 & 33 & 30 & 10 & 14 & 6 & 7 \\
& 5 & 25 & 16 & 20 & 14 & 13 & 12 \\
\hline \multirow{2}{*}{ Photo } & 6 & 12 & 12 & 25 & 1 & 48 & 2 \\
& 8 & 23 & 16 & 19 & 3 & 35 & 4 \\
\hline \multirow{2}{*}{ Regional } & 7 & 25 & 12 & 18 & 13 & 15 & 17 \\
& 9 & 32 & 25 & 10 & 9 & 18 & 6 \\
\hline
\end{tabular}

physical processes affecting the aerosol size distributions, we use statistical tools to reduce the complexity of this DMPS dataset.

\subsection{K-means clustering}

Nine K-means clusters were obtained, whose frequency varied between $2 \%$ and $27 \%$ (Table 2), with clusters 4 and 5 dominating the overall population (53\%). Whilst some clusters showed elevated concentrations for both high mass $\left(\mathrm{PM}_{\mathrm{x}}\right)$ and particle number $(\mathrm{N})$ distributions (i.e. cluster 3, 4,5 ), some were more notable for high $\mathrm{N}$ (i.e. cluster 1,2 ) or $\mathrm{M}$ (i.e. cluster 7). A curve-fitting programme was used to disaggregate the size distributions of each cluster into a number of lognormal distributions (nucleation, Aitken and accumulation) whose average aerosol size diameters are reported in Fig.S1. Further information related to each cluster is provided in Figs. 3-6, Tables 2-4 and Figs. SI1 and SI2. The Supplement section presents a detailed summary for each DMPS cluster. The nine individual clusters could be distributed into four groupings namely Dilution, Traffic, Photo and Regional categories. This additional categorisation was based not only upon their similar size distributions among each other (see Fig. 3a-d) but also by considering strong similarities between other parameters, particularly meteorological parameters and air mass trajectories. The reduction to four more-generic classifications was based on our data interpretation, and the average aerosol size distributions of each aerosol categories (obtained by averaging the DMPS clusters of each individual category) are presented in Fig. 3e. The 


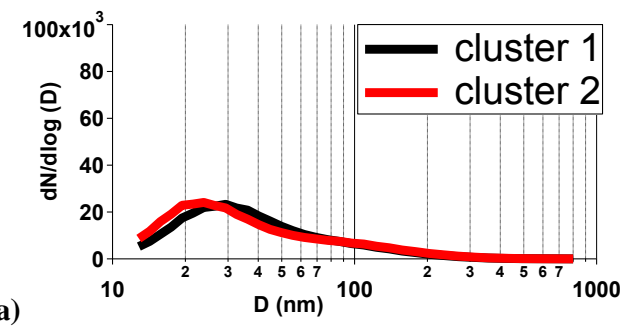

(a)

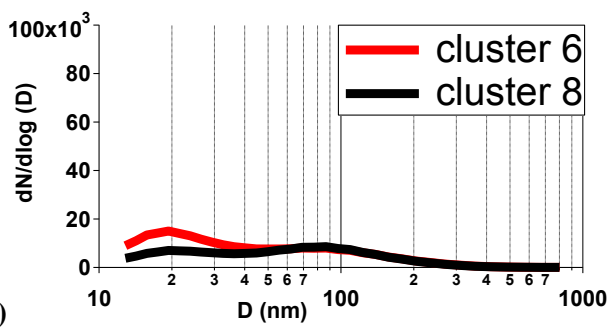

(b)

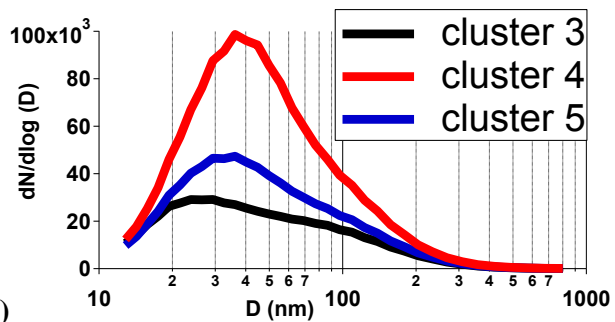

(d)

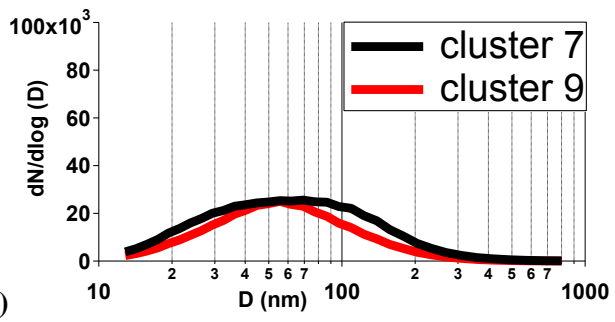

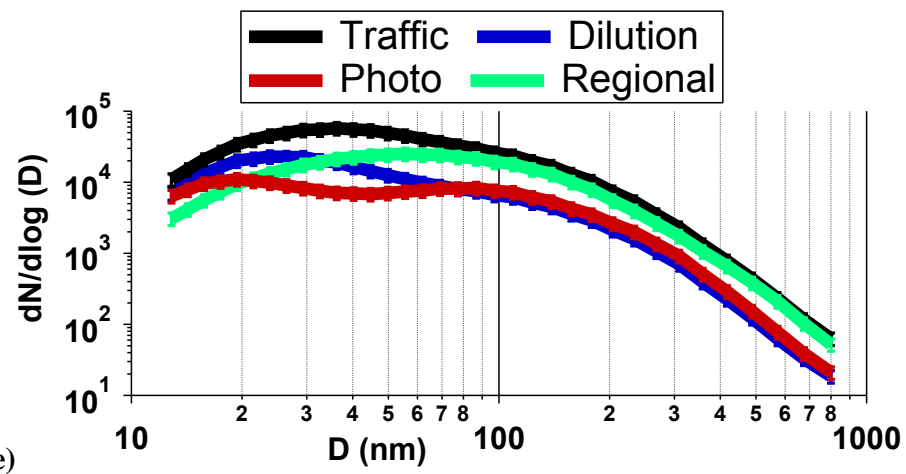

(e)

Fig. 3. K-means clusters for (a) Dilution, (b) Traffic, (c) Photochemical, (d) Regional and (e) Average number aerosol size distributions for each of the four groups.

main characteristics and related environmental parameters associated with the four main classifications are described below. An aerosol K-means cluster represents a particle size spectrum which is made through a superposition of individual sources and processes. Therefore, given that each cluster results from combinations of multiple factors, the name associated with it reflects only the main feature associated with the particle size spectrum and not merely one source or process.

\subsubsection{Dilution conditions}

Clusters 1 and 2 represent $12 \%$ of the total DMPS size distributions and their size distributions are presented in Fig. 3a. Cluster 1 has the peculiar feature of being associated with the lowest $\mathrm{PM}_{1}\left(14 \pm 8 \mu \mathrm{g} \mathrm{m}^{-3}\right), \mathrm{PM}_{2.5}$ $\left(18 \pm 10 \mu \mathrm{g} \mathrm{m}^{-3}\right)$ and $\mathrm{PM}_{10}\left(32 \pm 20 \mu \mathrm{g} \mathrm{m}^{-3}\right)$ concentrations; the lowest atmospheric pressure $(1002 \pm 50 \mathrm{mb})$, low relative humidity $(61 \pm 18 \%)$ and the highest average wind speed $\left(2.7 \pm 1.8 \mathrm{~m} \mathrm{~s}^{-1}\right)$ of all clusters (Table 2). Cluster 2 follows a similar pattern to cluster 1 . Both wind roses for these clusters point to a westerly direction (Fig. 4a-b). Clus- ter 1 did not present a clean annual seasonality (Fig. SI2), but was found to be predominantly associated with Atlantic air masses (64\% of the time, Table 3). By contrast, air masses associated with cluster 2 reflected a more south westerly origin (Atlantic West and NAF, Table 3). Cluster 2 peaked during summer and autumn (Fig. S2) whereas cluster 1 occurred mainly during colder months. The strong wind speeds associated with these two clusters are likely the reason for the low particle number and mass concentrations recorded during their occurrence. We associate this cluster with local pollution diluted by strong wind. Cluster 1 shows a similar bimodal size distribution with a major mode at $21-26 \pm 1 \mathrm{~nm}$ and a smaller Aitken mode at $58-63 \pm 8 \mathrm{~nm}$. It is important to remember that air arriving from the Atlantic will in most cases have traversed all of Spain (and possibly Portugal) and therefore collected significant pollution on the way. However, the main significance of Atlantic air masses is that they are faster moving and therefore cause enhanced dilution of local pollutants. These two clusters presented the lowest $\mathrm{PM}_{1} / \mathrm{PM}_{10}$ ratio (0.44) of all clusters, probably reflecting an enhanced resuspended dust contribution due to higher wind 


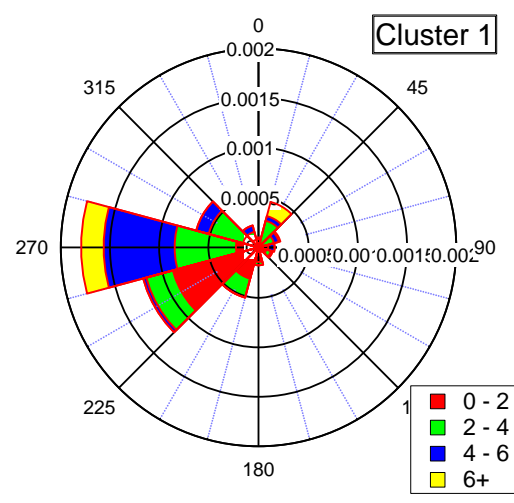

(a)

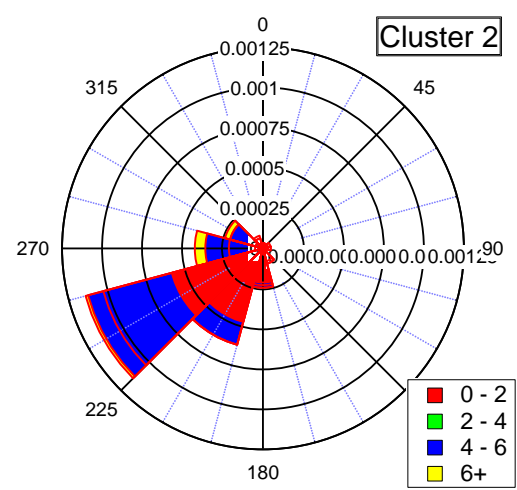

(b)

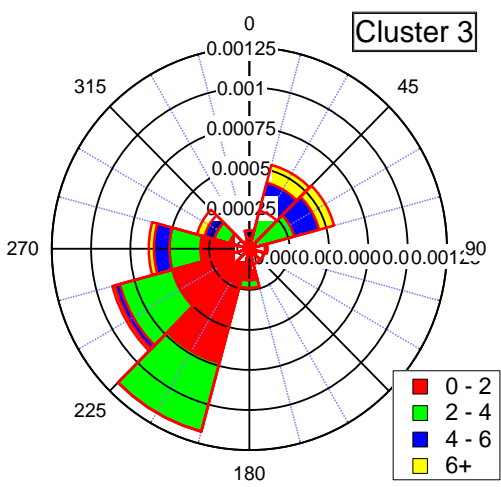

(c)

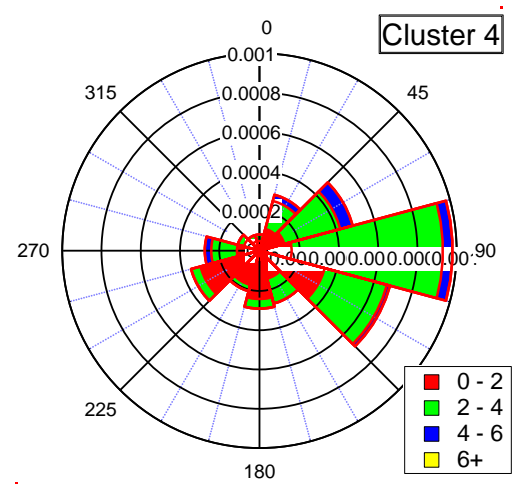

(d)

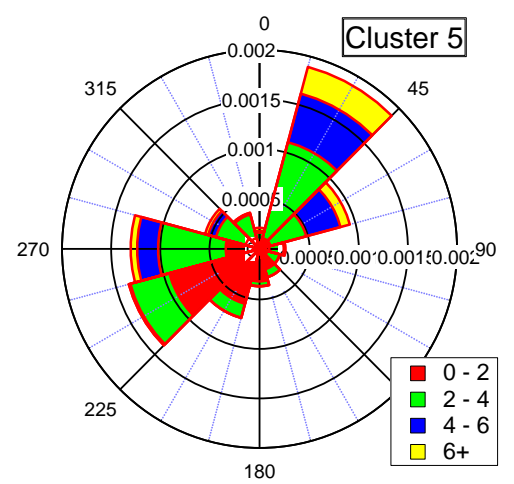

(e)

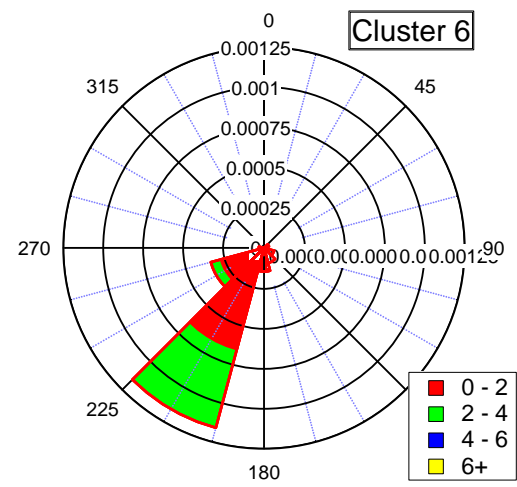

(f)

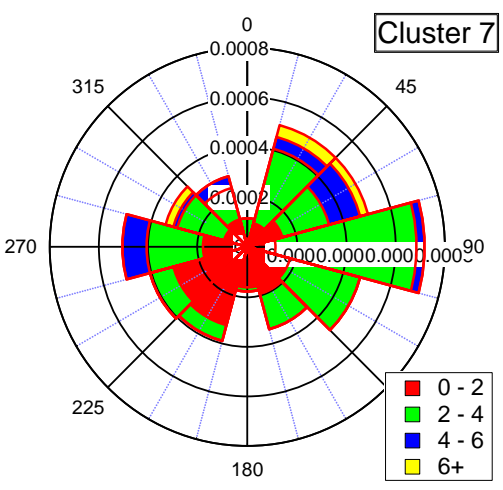

$(\mathrm{g})$

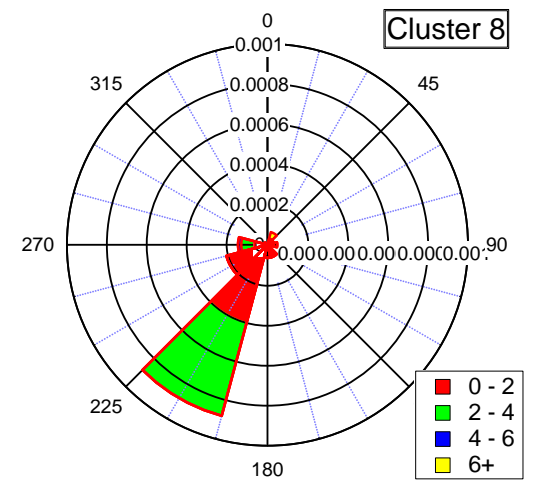

(h)

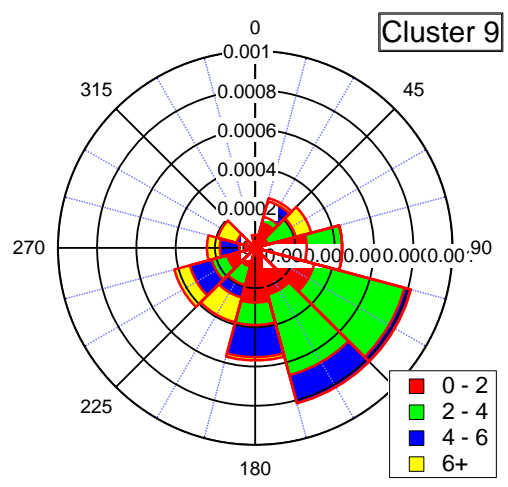

(i)

Fig. 4. Wind roses $\left(^{\circ}\right)$ associated with each DMPS cluster. Wind data from the meteorological observatory was used for the calculation. Colour plot represents the wind speed $\left(\mathrm{m} \mathrm{s}^{-1}\right)$. 
Table 4. Summary of the log normal fitting of K-means clustering and PMF analysis. When multi modality is found, relative contribution is given. Peak maximum values were found in the order of $18-36 \mathrm{~nm}, 41-90 \mathrm{~nm}$ and $103-315 \mathrm{~nm}$ for the nucleation, Aitken and accumulation modes, respectively.

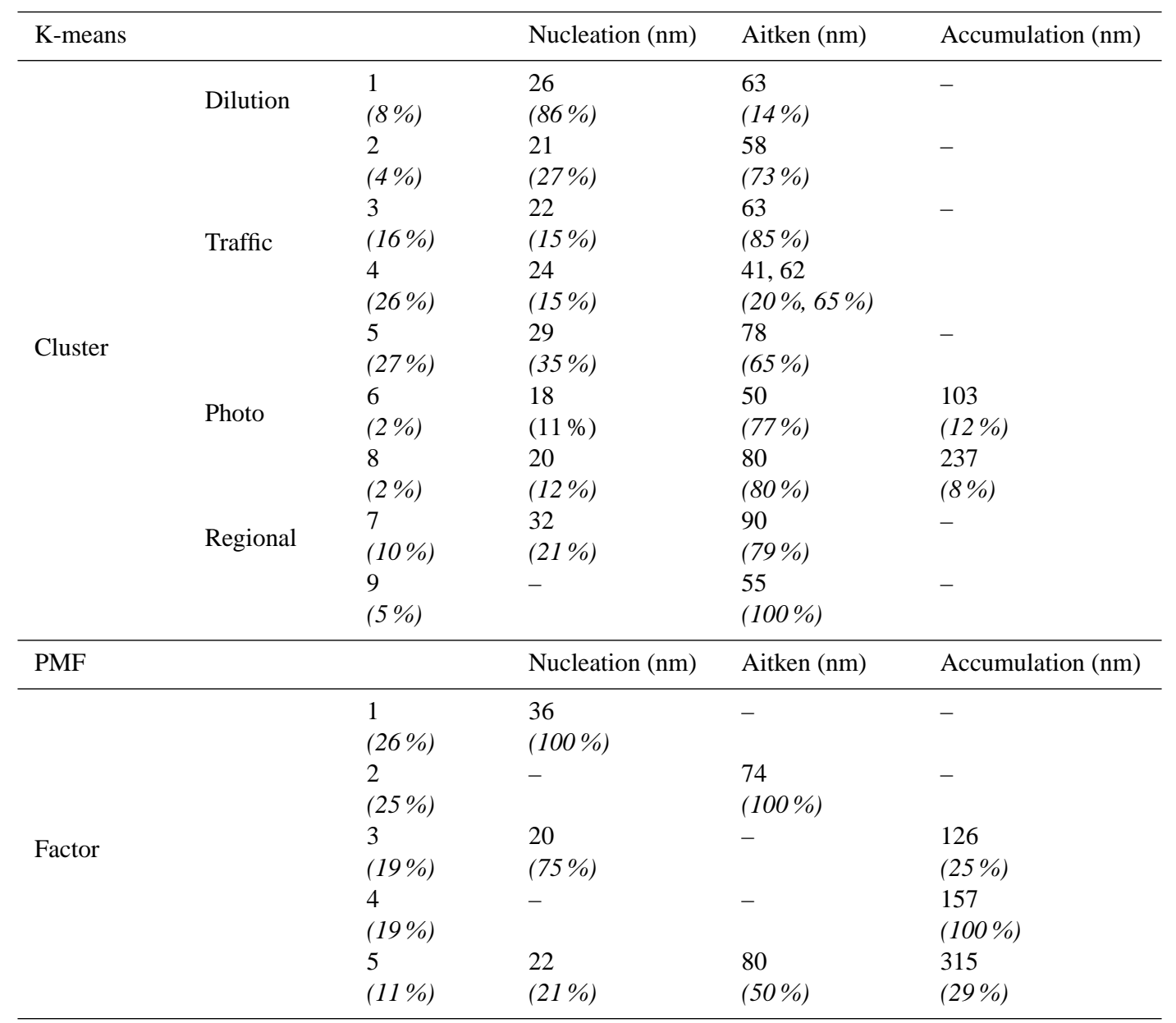

speeds. Their $\mathrm{NO}_{\mathrm{x}}$ and particle number concentration places them at the lower corner of the "Traffic" category (see Fig. 6).

\subsubsection{Traffic influence}

Cluster 3, 4, 5 (Fig. 3b) describe $69 \%$ of total DMPS distributions classified. The three clusters possess the highest particle number concentrations of all clusters (Table 2). Furthermore, cluster $4(26 \%)$ is associated with the highest concentrations of $\mathrm{CO}\left(0.6 \pm 0.5 \mathrm{mg} \mathrm{m}^{-3}\right)$ and $\mathrm{NO}_{2}\left(42 \pm 25 \mu \mathrm{g} \mathrm{m}^{-3}\right)$, and the lowest ozone concentrations $\left(29 \pm 24 \mu \mathrm{g} \mathrm{m}^{-3}\right.$, Table 3). Cluster 5 is also associated with high traffic-generated gaseous pollutant concentrations, the second highest of all clusters after cluster 4 . The association with traffic markers and a marked diurnal profile spiking during traffic rush hours (Fig. 5) suggest that primary traffic aerosols is the source dominating the profile of these particle size clusters. They lie towards the top right of the

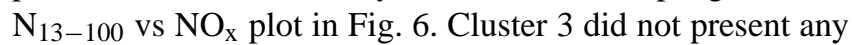
clear correlation with any gaseous pollutant nor with partic- ulate mass or meteorological data and it was the least clearly characterised of this study. It was associated with south-south westerly winds and was detected mainly during summer and autumn months. However, among all 4 categories, we found that clusters 3 possessed particle size spectra similar to clusters 4 and 5 (Fig. 3b) and for that reason it was allocated to this category. Further support comes from the position of this cluster in the $\mathrm{NO}_{\mathrm{x}}$ versus $\mathrm{N}_{13-100}$ plot (Fig. 6). These 3 clusters are all characterised by an aerosol size distribution with a nucleation mode at about 22-29 $\mathrm{nm}$ and an Aitken mode at 41-62 nm. The two Aitken modes of cluster 4 may be due to the enhanced polluted conditions associated with this cluster occurring mainly during winter time (Fig. SI2). Hence, the coarser Aitken mode of cluster 4 may be attributed to background pollution (Fig. SI1). The overall population of this aerosol category $(69 \%)$ is in line with the study of Pey et al. (2009) where fresh vehicle exhausts made the predominant contribution to the number concentration in all particle sizes $\left(\mathrm{N}_{13-800} ; 67 \%\right)$. 

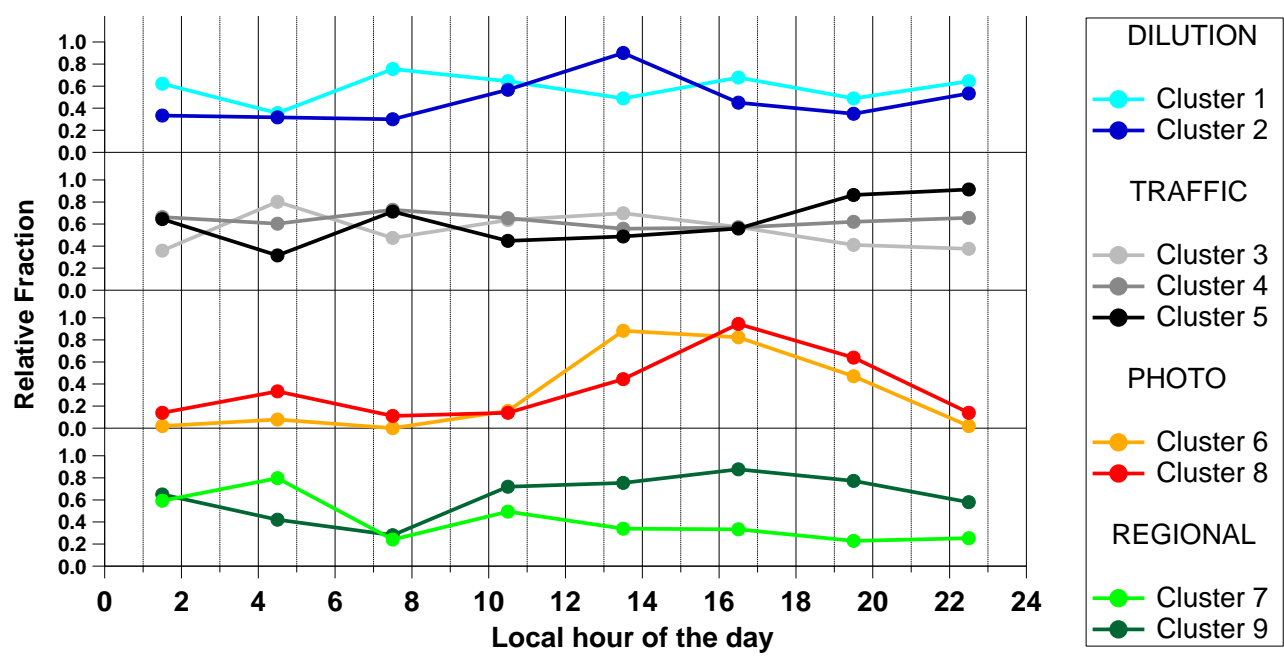

Fig. 5. Diurnal profiles for DMPS clusters. Cluster 3, 7 and 9 peaking during day or night time; cluster 1, 4 and 5 with a strong peak during the morning traffic hours and Cluster 2, 6 and 8 with a strong peak in the warmest part of the day.

\subsubsection{Summer photochemical conditions}

Cluster 6 and cluster 8 (Fig. 3c) represent only $4 \%$ of the total size distributions collected during the 2004. However, about $70 \%$ of these hourly DMPS size distributions occur during the months of July and August. This is also reflected in the highest average temperatures and the strongest solar radiation associated with these two clusters (Table 2). A limitation of this sub-cluster is that the whole summer month of June is not considered in this analysis (due to instrument failure) so there is probably an underestimation of this aerosol category. Clusters 6 and 8 presented unique properties: they were associated with the lowest concentrations of gaseous primary traffic pollutants but the highest ozone. Furthermore, $35-48 \%$ of the time this cluster was detected under regional summer air mass scenarios (Table 3). The decomposition of the particle size spectra of these two clusters show the smallest detected nucleation mode diameter at about $18-20 \mathrm{~nm}$ (Fig. SI1). We attribute this nucleation mode of this subgroup to photochemical nucleation events, with higher nucleating particle abundance in cluster 6 relative to cluster 8 . The position of the clusters to the bottom left of Fig. 6 (lowest $\mathrm{NO}_{\mathrm{x}}$ values suggesting less polluted atmospheric conditions favouring nucleation events) is consistent with this origin, although the relatively low values of $\mathrm{N}_{13-100}$ are surprising, but consistent with the low frequency of nucleation events. Wind roses of both clusters were found strongly pointing south west (Fig. 4), a typical pattern encountered during typical sea breeze conditions associated with regional summer air masses. The diurnal temporal variation was found to spike between 13:00 LT and 18:00 LT (Fig. 5). Bae et al. (2010) found an association between the condensation sink (CS) in the range of $8.35-283.9 \mathrm{~nm}$ and $\mathrm{PM}_{2.5}$ mass in the urban areas, consistent with our finding of photochemical nucle- ation events associated with the lowest PM concentrations (Table 2).

\subsubsection{Urban/Regional background conditions}

Cluster 7 and cluster 9 accounted for $12 \%$ of the total DMPS particle size spectra classified. Both clusters presented Aitken-accumulation modes more substantial than the nucleation mode (Fig. 3d). Cluster 7 (10\%, Fig. 3d) shows a bimodal size distribution with a mode at $32 \pm 1 \mathrm{~nm}$ and a stronger one at $90 \pm 3 \mathrm{~nm}$,. Cluster $9(5 \%)$ was the only one of all nine presenting a unimodal size distribution peaking at $55 \pm 1 \mathrm{~nm}$ (Figs. 3d, SI1). We attribute these to clusters to aged aerosols linked to regional background and/or urban background aged aerosols. However, these two clusters present opposite seasonality trends. Cluster 7 peaked mainly during winter time (with winter regional air masses, Table 3) whilst cluster 9 peaked mainly during the summer season (Fig. SI2). Additionally, cluster 7 shows up mainly during nighttime while cluster 9 occurs mainly during daytime (Fig. 5). Cluster 9 presented the highest PM loadings of all nine clusters: $\mathrm{PM}_{1}$ of $32 \pm 18 \mu \mathrm{g} \mathrm{m}^{-3}, \mathrm{PM}_{2.5}$ of $38 \pm 21 \mu \mathrm{g} \mathrm{m}^{-3}$ and $\mathrm{PM}_{10}$ of $52 \pm 30 \mu \mathrm{g} \mathrm{m}^{-3}$. Cluster 7 was also associated with high PM values, the second highest PM concentrations of $\mathrm{PM}_{1}\left(24 \pm 14 \mu \mathrm{g} \mathrm{m}^{-3}\right) \mathrm{PM}_{2.5}$ $\left(28 \pm 11 \mu \mathrm{g} \mathrm{m}^{-3}\right)$ and $\mathrm{PM}_{10}\left(44 \pm 33 \mu \mathrm{g} \mathrm{m}^{-3}\right)$. Regional and long range transported aerosol size distributions possess the highest hourly values of particulate mass but do not present high particle number concentrations (Table 2). Nitrate containing aerosol is a good candidate for the accumulation mode detected during wintertime, whilst sulphate containing aerosols may contribute to the unimodal distribution seen during summer. Finally, cluster 7 was found to present the lowest daytime occurrence (40\%) among all clusters as well as the highest $\mathrm{PM}_{1} / \mathrm{PM}_{10}$ ratio (0.62). Regional transport 


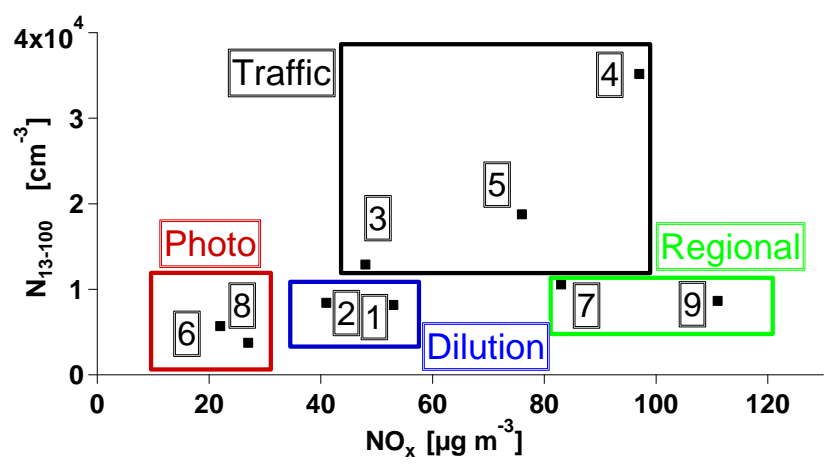

Fig. 6. Particle number concentrations $\mathrm{N}_{13-100 n m}$ versus $\mathrm{NO}_{\mathrm{x}}$. Points are average values for the nine solutions indentified by $\mathrm{k}$ means clustering analysis, merged as discussed in Sect. 4.1 as Dilution, Traffic, Photo-nucleation and regional scenarios.

is a major source of secondary particulate matter (reflected both in $\mathrm{PM}_{1}$ and $\mathrm{PM}_{10}$ ) but it seems less important for particle number concentrations $(12-19 \%$ for the Aitkenaccumulation modes). In a previous study (Pey et al., 2009), about $25 \%$ of the total particle number concentration was attributed to secondary inorganic particles. Its position in Fig. 6 (low $\mathrm{N}_{13-100}$ with high $\mathrm{NO}_{\mathrm{x}}$ ) is consistent with aged polluted air. The wind-direction association suggests that the air masses associated with cluster 9 arrived from the sea with the sea breeze, possibly having originated over land during the preceding night and travelled to sea with the land breeze.

\subsection{PMF analysis}

By considering the likelihood of factors occurring in the output from PMF, a 5 factor solution was chosen using standard deviation constants $T=0.0038$ and $V=0.1$ - see the supplementary information provided by Harrison et al. (2011). The maximum rotation was reduced to the smallest value possible by increasing the value of FPEAK from 0.0 to 0.4 .

The results of the PMF analysis are summarised in Fig. 7, which shows the number spectra associated with each factor as well as diurnal profiles and wind rose patterns.

- Factor 1 is the largest contributor to particle number $(26 \%)$ and presents a unimodal size distribution centered at $36 \pm 1 \mathrm{~nm}$. The strong diurnal profile (peaking during traffic rush hours times at 07:00 LT and 21:00 LT) indicate those are primary traffic related exhaust particles. This mode is somehow in between the position of the modes at around $20 \mathrm{~nm}$ associated with nucleation mode particles generated during dilution of diesel exhaust emissions (Ntziachristos et al., 2007) and at around $50 \mathrm{~nm}$ corresponding to solid carbonaceous particles from diesel exhaust (Shi et al., 2000) This factor lacked of obvious directionality (modest north-south east wind direction association) and did not present a clear seasonal profile either.
- Factor 2 is the second largest contributor to particle number (25\%) and presents a unimodal size distribution centered at $74 \pm 1 \mathrm{~nm}$. It presents a remarkably similar wind rose and diurnal profile to Factor 1, and it is attributed to the solid mode exhaust particle component (Casati et al., 2007; Harrison et al., 2011).

- Factor 3 (19\% of total particle number) shows a main particle number nucleation mode at $19 \pm 1 \mathrm{~nm}(75 \%$ of the aerosol size distribution area), making it the smallest aerosol size mode factor obtained by the PMF analysis. However, it should be borne in mind that only particles larger than $13 \mathrm{~nm}$ were measured. A minor accumulation mode is also found at $126 \pm 4 \mathrm{~nm}(25 \%$ of the area, Fig. 7). Unlike clusters 1 and 2, this factor shows a directionality pointing to the south sector and seasonality shifted towards summer times. A unique diurnal profile shows, between the morning and evening traffic rush hour spikes, a minor third spike peaking during the warmest part of the day. Whilst we attribute the two morning and evening spikes to the nucleation mode particles generated during dilution of diesel exhaust emissions, the midday peak is attributed to photochemical nucleation events. Decomposition of the diurnal profiles shows $\mathrm{N}_{13-800}$ particle concentrations attributed to Factor 3 apportioned to traffic rush hours (06:00 LT, 21:00 LT) for $82 \%$ of the time, leaving the photochemical component at $18 \%$. It is likely those percentages would be different if $\mathrm{N}_{<13}$ were considered.

- Factor 4 by contrast possesses small particle number concentrations and a unimodal accumulation mode size distribution peaking at $157 \pm 3 \mathrm{~nm}(19 \%$, Fig. 7). This is also reflected in a large contribution to the volume size distribution at $400 \pm 30 \mathrm{~nm}$. Factor 4 showed marked directionality to the south west sector and was found predominantly in summer. It was strongly correlated with $\mathrm{PM}_{1}$ and $\mathrm{PM}_{10}$ mass concentrations. We attribute this to regional pollution and enhanced dust present during summer time (Amato et al., 2009).

- Factor 5 (11\% of total particle number) showed a main Aitken mode at $80 \pm 1 \mathrm{~nm}(50 \%$ of total area) and two smaller modes at $22 \pm 1 \mathrm{~nm}$ and $315 \pm 50 \mathrm{~nm}(21 \%$ and $29 \%$ of total area, respectively). The size distribution, the flat diurnal profile and lack of obvious directionality suggests that this is background accumulation mode aerosol containing also a small nucleation mode component. Cluster 5 was also associated with the summer months.

When considering statistical correlations between PMF factors, significant relationships (obtained by comparing the factor's temporal trends, valid at $\mathrm{p}$-value $<0.05)$ were found only between factor 1 and factor $2\left(R^{2}=0.58\right)$ and between factor 4 and factor $5\left(R^{2}=0.48\right)$. This further suggests that 
PMF

Factor 1
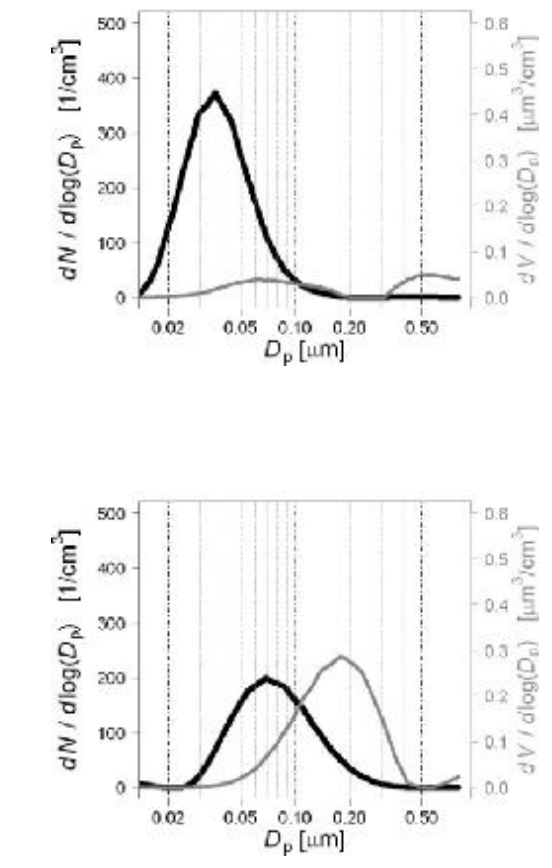

PMF

Factor 2

PMF

Factor 3
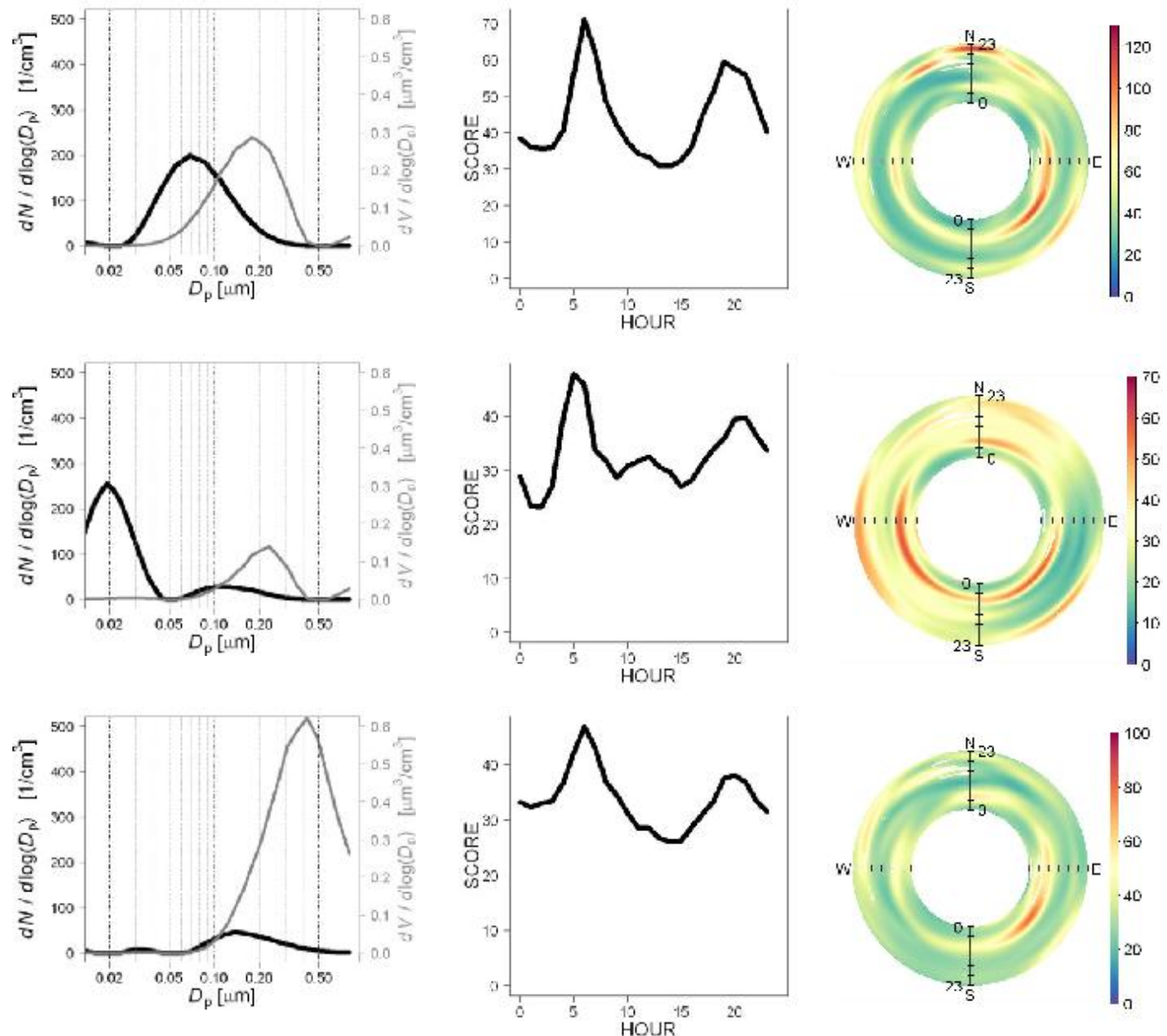

PMF

Factor 4
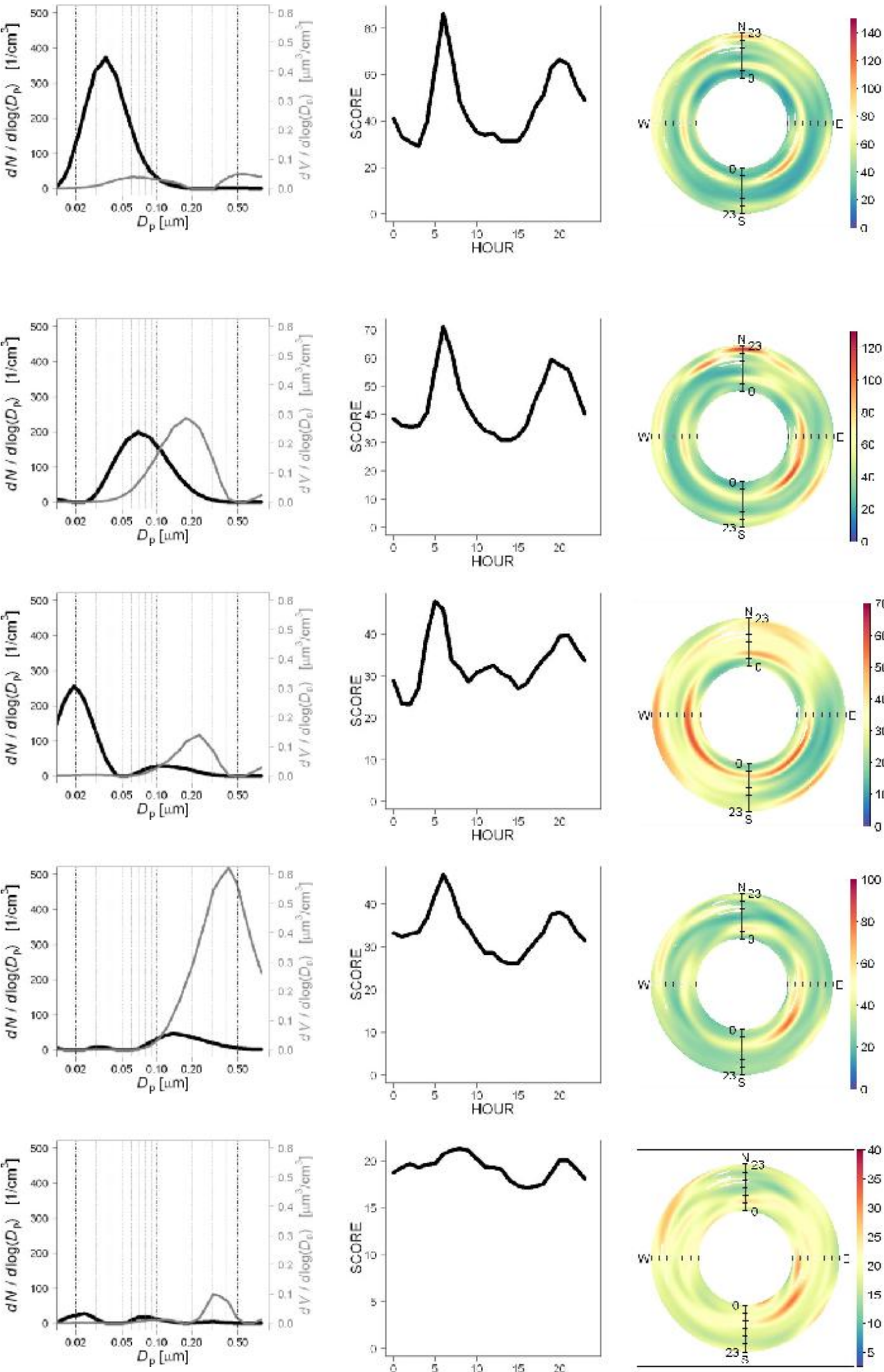

\section{0} 100

.80
.60
.40
.20
0
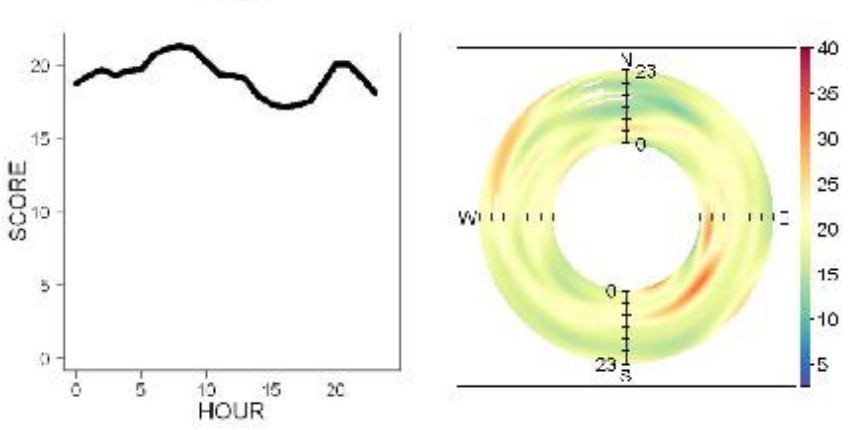

Fig. 7. Aerosol number (dark line, $d \mathrm{~N} / d \log \left(D_{\mathrm{p}}\right)$ ) and volume (pale line, $d \mathrm{~V} / d \log \left(D_{\mathrm{p}}\right)$ ) size-resolved size distributions, diurnal patterns and wind roses for the five factors obtained by the PMF analysis. 
Table 5. Summary of mode decomposition K-means clustering and PMF analysis.

\begin{tabular}{lllll}
\hline Method & \multicolumn{5}{c}{$\%$ of Aerosol mode } \\
\hline \multirow{3}{*}{ K-means } & Nucleation & Aitken & Accumulation & TOTAL \\
PMF & $39 \%$ & $49 \%$ & $18 \%$ & $100 \%$ \\
\hline
\end{tabular}

factor 1 and 2 are likely linked to the same source (traffic) whereas factor 4 and factor 5 are more associated with background aerosols. Factor 3 seems to be an independent factor and likely a combination of multiple sources and processes (traffic nucleation mode and particle formation events).

\section{Discussion and comparison between aerosol size distribution apportioning methods}

By applying K-means clustering, this study shows that highly varied size distributions are found in the Barcelona urban atmosphere at different times, which can be interpreted in terms of the known sources and meteorological processes affecting the particles. This analysis allows quantification of the temporal occurrence of a given aerosol size distribution cluster. However, such size distributions are often composed of nucleation (below $40 \mathrm{~nm}$ ), Aitken (between $40 \mathrm{~nm}$ and $100 \mathrm{~nm}$ ) and accumulation (above $100 \mathrm{~nm}$ ) modes, making the aerosol source apportionment of each component a challenging task. By contrast, PMF allows separation of different modes by disaggregating aerosol size distributions. Indeed, our PMF analysis found unique factors describing the nucleation (Factor 3), the Aitken (Factor 2) and the accumulation (Factor 4) modes (Fig. 7). The component log-normal modal distributions obtained from disaggregation of K-means clusters are compared to the PMF factors obtained (Table 4). Table 5 summarises the mean aerosol diameter obtained for each peak fitted to the aerosol size distributions obtained by $\mathrm{K}$-means and PMF analysis. Table 5 shows the remarkably similar picture we obtain by using two different techniques herein compared for the first time (Beddows et al., 2009, Harrison et al., 2011); allowing quantification for $\mathrm{N}_{13-800}$ of the relative contribution of the nucleation, Aitken and accumulation modes (33-39\%, 39-49\% and 18-22\%, respectively).

Further evidence of the agreement of the two methods comes from the source identification of traffic and photochemical nucleation $\left(D_{\mathrm{p}}>13 \mathrm{~nm}\right)$ related particle concentrations. Wherever we are confident, we attribute particle size modes for traffic and photochemically generated particles. This is mainly obtained from diurnal profiles and meteorological associations described in Section 3. We find direct vehicle exhausts contribute dominantly (62-66\%) to the total particle number concentration (in line with the study of Pey et al., 2009), with a slightly higher proportion distributed towards the nucleation mode $(34 \%)$ relative to the
Aitken mode (28-32\%). Photochemically induced nucleation of secondary particles (Kulmala et al., 2004) is a source of particles, although in this dataset it appears to be a minor one $(2-3 \%)$. By using a chemically based source apportionment tool, the study of Pey et al. (2009) found this fraction represents of $23 \%\left(\mathrm{~N}_{13-20}\right)$, probably overestimating them due to the much lower time resolution used (24:00 LT). Overall, this study and the one of Pey et al., (2009) suggest that the road traffic appears to be the most important source of sub-micrometric aerosols, but other sources (urban and regional background air pollution) may also not be negligible under specific meteorological conditions.

It should be kept in mind that only particles bigger than $13 \mathrm{~nm}$ are considered in this study. Reche et al. (2011) recently showed that in southern Europe maximum particle number concentrations levels $(\mathrm{N}>2.5 \mathrm{~nm})$ coinciding with minimum black carbon levels are usually recorded at midday, suggesting photochemical nucleation is an important source of UF particles in the urban atmosphere of a number of cities in southern Europe. The present study suggest that photochemical nucleation events take place during summertime, but such particles often fail to reach the lowest DMPS size range used in this study $(13 \mathrm{~nm})$. High urban condensation sinks are likely to be the reason for such particles not to growth further (Kumar et al., 2008). Moreover, traffic particles evaporate to sizes smaller than typical DMPS size ranges and therefore both DMPS and CPCs should be deployed simultaneously in order to fully elucidate the dynamic of UF particles in the urban atmosphere (Dall'Osto et al., 2011b).

Recent aerosol size resolved particle number concentration studies from the SAPUSS project (Solving Aerosol Problems by Using Synergistic Strategies, Dall'Osto et al., 2012a) indeed shows that nucleating particles cannot easily grow within the urban agglomerate of Barcelona, but such particles are able to grow while being transported away from the city centre with the afternoon sea breeze (Dall'Osto et al., 2012b). Finally, it is worth to mention that the chemical composition and volatility of photochemically produced and traffic emitted UF particles is likely to be very different, leading to different lifetimes and behaviours of the UF particles generated by the two different production mechanisms.

\section{Implications and conclusions}

Aerosol size distributions sampled in an urban background location in Barcelona (NE Spain) during the 2004 (62\% data coverage) were analyzed by both $\mathrm{k}$-means clustering and PMF techniques. The k-means analysis identified 9 distinct aerosol size distributions. These 9 clusters could be further grouped into four more generic particle size spectra categories: traffic $(69 \%)$, dilution (15\%), photo $(4 \%)$ and regional $(12 \%)$. During winter months, high particle number concentrations attributed to traffic aerosol sources dominate the aerosol size distributions; whereas under North Atlantic 
advections such concentrations are diluted, also during traffic rush hours periods.

Concerning particles between $13 \mathrm{~nm}$ and $800 \mathrm{~nm}$, we find vehicular traffic is a much bigger source of particles (62$66 \%)$ relative to photochemical induced nucleation events (2-3\%). Aerosol size distributions modes related to PM regional transport are different from the traffic related ones; they are shifted toward higher accumulation modes and associated with the highest recorded $\mathrm{PM}_{1}, \mathrm{PM}_{2.5}$ and $\mathrm{PM}_{10}$ concentrations. To our knowledge, this is the first study where both k-means clustering and PMF analysis have been applied to a large aerosol size distribution dataset. Our application has proved especially successful in apportioning particle number concentration (size range 13-800nm) with two different techniques, giving good agreement.

As pointed out by Asmi et al. (2011), long term datasets can be used for model measurement comparison point-ofview. Regional-scale modelling studies are not able to reproduce sufficient aerosol particle concentrations well, especially for ultrafine particles with diameters less than $100 \mathrm{~nm}$ (Park et al., 2006; Fan et al., 2006, Elleman and Covert, 2009a, b). In the urban environment, simulated number size distributions are considerably less accurate than mass size distributions and are difficult to represent in air quality models due to large sub-grid-scale concentration gradients (Kelly 2011). The relationships between air quality parameters and the contribution of local sources to ambient pollutant concentrations is yet not fully understood (Kwasny et al. 2010; Williams and Carslaw, 2011; Reche et al., 2011). Additionally, despite considerable toxicological evidence of the potential detrimental effects of these particles on human health, the appropriate metric for evaluating health effects is still not clear. The current data analysis shows that our understanding of large DMPS datasets can be greatly simplified (i.e. Fig. 6), allowing to better describe the source origin of airborne particles and their correlations with other air quality parameters.

\section{Supplementary material related to this article is available online at: http://www.atmos-chem-phys.net/12/ 10693/2012/acp-12-10693-2012-supplement.pdf.}

Acknowledgements. FP7-PEOPLE-2009-IEF, Project number 254773, SAPUSS - Solving Aerosol Problems Using Synergistic Strategies (Marie Curie Actions - Intra European Fellowships. Manuel Dall'Osto). This study was previously supported by research projects from the D. G. de Calidad y Evaluación Ambiental (Spanish Ministry of the Environment) and the Plan Nacional de I p D (Spanish Ministry of Education and Science [CGL200405984_C07-02/CLI, CGL2007-62505/CLI (DOASUR)], Spanish Ministry of Science and Innovation [CGL2010-19464 (VAMOS)]), a collaboration agreement CSIC-JRC, and the Departament de Medi Ambient from the Generalitat de Catalunya, who kindly supported data of gaseous pollutants. Meteorological data were provided by the Servei Meteorolo'gic de Catalunya and by the Department of Physics from the University of Barcelona. NCAS for David Beddows. Rita Van Dingenen (European Commission, DG Joint Research Centre, Institute for Environment and Sustainability, Italy) are also acknowledged for DMPS measurements.

Edited by: R. Vecchi

\section{References}

Alam, A.; Shi, J. P., and Harrison, R. M.: Observations of New Particle Formation in Urban Air, J. Geophys. Res., 108, 4093-4107, 2003.

Amato, F., Pandolfi, M., Escrig, A., Querol, X., Alastuey, A., Pey, J., Perez, N., and Hopke, P. K.: Quantifying road dust resuspension in urban environment by multilinear engine: A comparison with PMF2, Atmos. Environ., 43, 2770-2780, 2009.

Atkinson, R. W., Fuller, G. W., Anderson, H. R., Harrison, R. M., and Armstrong B.: Urban ambient particle metrics and health: A time series analysis, Epidemiology, 21, 501-511, 2010.

Asmi, A., Wiedensohler, A., Laj, P., Fjaeraa, A.-M., Sellegri, K., Birmili, W., Weingartner, E., Baltensperger, U., Zdimal, V., Zikova, N., Putaud, J.-P., Marinoni, A., Tunved, P., Hansson, H.C., Fiebig, M., Kivekäs, N., Lihavainen, H., Asmi, E., Ulevicius, V., Aalto, P. P., Swietlicki, E., Kristensson, A., Mihalopoulos, N., Kalivitis, N., Kalapov, I., Kiss, G., de Leeuw, G., Henzing, B., Harrison, R. M., Beddows, D., O’Dowd, C., Jennings, S. G., Flentje, H., Weinhold, K., Meinhardt, F., Ries, L., and Kulmala, M.: Number size distributions and seasonality of submicron particles in Europe 2008-2009, Atmos. Chem. Phys., 11, 5505-5538, doi:10.5194/acp-11-5505-2011, 2011.

Bae, M.-S., Schwab, J. J., Hogrefe, O., Frank, B. P., Lala, G. G., and Demerjian, K. L.: Characteristics of size distributions at urban and rural locations in New York, Atmos. Chem. Phys., 10, 45214535, doi:10.5194/acp-10-4521-2010, 2010.

Beddows, D. C. S., Dall'Osto, M., amd Harrison, R. M.: Cluster analysis of rural, urban and curbside atmospheric particle size data, Environ. Sci. Technol. 43, 4694-4700, 2009.

Casati, R., Scheer, V., Vogt, R., and Benter, T.: Measurement of nucleation and soot mode particle emission from a diesel passenger car in real world and laboeratory in situ dilution, Atmos. Environ., 41, 2125-2135, 2007.

Charron A., Birmili, W., and Harrison, R. M.: Factors Influencing New Particle Formation at the Rural Site, Harwell, United Kingdom, J. Geophys. Res., 112, D14210, doi:10.1029/2007JD008425, 2007

Costabile, K., Birmili, W., Klose, S., Tuch, T., Wehner, B., Wiesensohler, A., Franck, U., König, K., Sonntag, A.: Spatio-temporal variability and principal components of the particle number size distribution in an urban atmosphere, Atmos. Chem. Phys., 9, 3163-3196, doi:10.5194/acp-9-3163-2009, 2009.

Dall'Osto, M., Monahan, C., Greaney, R., Beddows, D. C. S., Harrison, R. M., Ceburnis, D., and O'Dowd, C. D.: A statistical analysis of North East Atlantic (submicron) aerosol size distributions, Atmos. Chem. Phys., 11, 12567-12578, doi:10.5194/acp11-12567-2011, 2011a.

Dall'Osto, M., Thorpe, A., Beddows, D. C. S., Harrison, R. M., Barlow, J. F., Dunbar, T., Williams, P. I., and Coe, H.: Remarkable dynamics of nanoparticles in the urban atmosphere, At- 
mos. Chem. Phys., 11, 6623-6637, doi:10.5194/acp-11-66232011, 2011b.

Dall'Osto, M., Querol, X., Alastuey, A., O’Dowd, C., Harrison, R. M., Wenger, J., and Gómez-Moreno, F. J.: On the spatial distribution and evolution of ultrafine aerosols in urban air, Atmos. Chem. Phys. Discuss., 12, 16603-16646, doi:10.5194/acpd-1216603-2012, 2012a.

Dall'Osto, M, A. Alastuey, M. A. Pedemonte, B. L. van Drooge, M. Pandolf, M. C. Minguillo, F. Amato, T. Moreno, J. Pey, C. Reche, M. Cusak, M. Viana, A. Roca, J . Gietl, D. Beddows, Roy M. Harrison, J. Wenger, E. McGillicuddy, J. Sodeau, R. Healy, D. Ceburnis, G. Martucci, C. O’Dowd, F. Lucarelli, S. Nava, J. L. Jimenez, F. Gomez Moreno, B. Artinono, A. S. H. Prevot, L. Pfaffenberger, S. Frey, F. Wilsenack, S. Ng, D. Worsnop, D. Casabona Fina, P. Jiménez Guerrero, X. Querol - Presenting SAPUSS: Solving Aerosol Problems by Using Synergistic Strategies, Atmos. Chem. Phys. Discuss., 12, 18741-18815, doi:10.5194/acpd-12-18741-2012, 2012b.

Davidson, C., Phalen, R., and Solomon, P.: Airborne particulate matter and human health: a review, Aerosol Sci. Technol., 39, 737-749, 2005.

Dimitriadou, E. Hornik, K., Leisch, F., Meyer, D., and Weingessel, A.: Misc Functions of the Department of Statistics (e1071), TU Wien, package version 1.5-25, http://CRAN.R-project.org/ package $=\mathrm{e} 1071$, (last access: November 2012), 2011.

Draxler, R. R., Rolph, G. D.: Hysplit (hybrid single-particle lagrangian integrated trajectory) model, http://www.arl.noaa.gov/ ready/hysplit4.html), (last access: November 2012), NOAA Air Resources Laboratory, Silver Spring, MD, USA, 2003.

Elleman, R. A. and Covert, D. S.: Aerosol size distribution modeling with the Community Multiscale Air Quality modeling system in the Pacific Northwest: 1. Model comparison to observations, J. Geophys. Res., 114, D11206, doi:10.1029/2008JD010791, 2009a.

Elleman, R. A. and Covert, D. S.: Aerosol size distribution modeling with the Community Multiscale Air Quality modeling system in the Pacific Northwest: 2. Parameterizations for ternary nucleation and nucleation mode processes, J. Geophys. Res., 114, D11207, doi:10.1029/2009JD012187, 2009b.

EEA CSI 004-Exceedance of air quality limit values in urban areas (version 2), available at: http://themes.eea. europa.eu/IMS/IMS/ISpecs/ISpecifkcation20080701123452/

IAssessment1243521792257/viewcontent (last access: November 2012), 2009.

EC: Guidance to member states on $\mathrm{PM}_{10}$ equivalent monitoring and intercomparisons with the reference method". EC Woking Group on PM. Air Quality Steering Group, D.G. Environment, final report February 2001. 68 pp., available at: http://europa.eu. int/comm/environment/air/pdf/finalwgreporten.pdf (last access: November 2012), , 2001.

Fan, J., Zhang, R., Collins, D., and Li G.:, Contribution of secondary condensable organics to new particle formation: A case study in Houston, Texas, Geophys. Res. Lett., 33, L15802, doi:10.1029/2006GL026295, 2006.

Harrison, R. M., Shi, J. P., Xi, S. H., Khan, A., Mark, D., Kinnersley, R., and Yin, J. X.: Measurement of number, mass and size distribution of particles in the atmosphere, Philosoph. Trans. Roy. Soc. Ldn. Ser. A Math. Phys. Eng. Sci., 358, 2567-2579, 2000 a.
Harrison, R. M. and Yin J.: Particulate matter in the atmosphere: Which particle properties are important for its effects on health?, Sci. Total Environ. 249, 85-101, 2000 b.

Harrison, R. M., Beddows, D. C. S., and Dall'Osto, M.: PMF Analysis of wide-range particle size spectra collected on a major highway, Environ. Sci. Technol., 45, 5522-5528, 2011.

Hussein, T., Puustinen, A., Aalto, P. P., Mäkelä, J. M., Hämeri, K., and Kulmala, M.: Urban aerosol number size distributions, Atmos. Chem. Phys., 4, 391-411, doi:10.5194/acp-4-391-2004, 2004.

Hussein, T., Karppinen, A., Kukkonen, J., Härkönen, J., Aalto, P. P., Hämeri, K., Kerminen, V.-M., and Kulmala, M.: Meteorological dependence of size-fractionated number concentrations of urban aerosol particles, Atmos. Environ., 40, 1427-1440, 2006

Jeong, C.-H., Evans, G. J., McGuire, M. L., Chang, R. Y.-W., Abbatt, J. P. D., Zeromskiene, K., Mozurkewich, M., Li, S.-M., and Leaitch, W. R.: Particle formation and growth at five rural and urban sites, Atmos. Chem. Phys., 10, 7979-7995, doi:10.5194/acp10-7979-2010, 2010.

Kelly, J. T., Avise, J., Cai, C., and Kaduwela, A. P.: Simulating Particle Size Distributions over California and Impact on Lung Deposition Fraction, Aerosol Sci. Technol., 45, 148-162, 2011.

Kulmala, M., Vehkamäki, H., Petaäjä , T., Dal Maso, M., Lauri, A., Kerminen, V.-M., Birmili, W., and McMurry, P. H.: Formation and growth rates of ultrafine atmospheric particles: A review of observations, J. Aerosol Sci., 35, 143-176, 2004.

Kumar, P., Fennell, P., Langley, D., and Britter, R.: Pseudosimultaneous measurements for the vertical variation of coarse, fine and ultra fine particles in an urban street canyon, Atmos. Environ., 42, 4304-4319, 2008.

Kwasny, F., Madl, P., and Hofmann, W.: Correlation of Air Quality Data to Ultrafine Particles (UFP) Concentration and Size Distribution in Ambient Air, Atmosphere, 1, 3-14, 2010.

Millan, M., Salvador, R., Mantilla, E., and Kallos, G.: Photooxidant dynamics in the Mediterranean basin in summer: results from European research projects, J. Geophys. Res., 102, 88118823, 1997.

Ntziachristos, L., Ning, Z., Geller, M. D., and Sioutas, C.: Particle concentration and characteristics near a major freeway with heavy-duty diesel traffic, Environ. Sci. Technol., 41, 2223-2230, 2007.

Park, S.-K., Marmur, A., Kim, S. B., Tian, D., Hu, Y., McMurry, P. H., and Russell, A. G.: Evaluation of fine particle number concentrations in CMAQ, Aerosol Sci. Technol., 40, 985-996, doi:10.1080/02786820600907353, 2006.

Pérez, N., Pey, J., Querol, X., Alastuey, A., López, J. M., and Viana, M.: Partitioning of major and trace components in $\mathrm{PM}_{10}, \mathrm{PM}_{2.5}$, $\mathrm{PM}_{1}$ at an urban site in Southern Europe, Atmos. Environ., 42, 1677-1691, 2008.

Pey, J., Rodríguez, S., Querol, X., Alastuey, A., Moreno, T., Putaud, J. P., and Van Dingenen, R.: Events and cycles of urban aerosols in the western Mediterranean, Atmos. Environ., 42, 9052-9062, 2008.

Pey, J., Querol, X., Alastuey, A., Rodríguez, S., and Putaud, J. P.: Source apportionment of urban fine and ultra-fine particle number concentration in a western Mediterranean city, Atmos. Environ. 43, 4407-4415, 2009.

Pope, C. A. III, Burnett, R. T., Thun, M. J., Calle, E. E. Krewski, D., Ito, K., and Thurston, G. D.: Lung cancern, cardiopul- 
monary mortality, and long-term exposure, JAMA, 287, 11321141, 2002.

Querol, X., Alastuey, A., Rodríguez, S., Plana, F., Ruiz, C. R., Cots, N., Massague, G., and Puig, O.: $\mathrm{PM}_{10}$ and $\mathrm{PM}_{2.5}$ source apportionment in the Barcelona metropolitan area, Catalonia, Spain, Atmos. Environ., 35/36, 6407-6419, 2001.

Querol, X., Alastuey, A., Ruiz, C. R., Artinano, B., Hansson, H. C., Harrison, R. M., Buringh, E., ten Brink, H. M., Lutz, M., Bruckmann, P., Straehl, P. and Schneider, J.: Speciation and origin of $\mathrm{PM}_{10}$ and $\mathrm{PM}_{2.5}$ in selected European cities, Atmos. Environ., 38, 6547-6555, 2004.

Reche, C., Querol, X., Alastuey, A., Viana, M., Pey, J., Moreno, T., Rodríguez, S., González, Y., Fernández-Camacho, R., de la Rosa, J., Dall'Osto, M., Prévôt, A. S. H., Hueglin, C., Harrison, R. M., and Quincey, P.: New considerations for PM, black carbon and particle number concentration for air quality monitoring across different European cities, Atmos. Chem. Phys., 11, 6207-6227, doi:10.5194/acp-11-6207-2011, 2011.

Rodriguez, S., Querol, X., Alastuey, A., Kallos, G., and Kakaliagou, O.: Saharan dust contributions to $\mathrm{PM}_{10}$ and TSP levels in Southern and Eastern Spain, Atmos. Environ., 35, 20 2433-2447, 2001.

Rodríguez, S., Van Dingenen, R., Putaud, J.-P., Dell'Acqua, A., Pey, J., Querol, X., Alastuey, A., Chenery, S., Ho, K.-F., Harrison, R., Tardivo, R., Scarnato, B., and Gemelli, V.: A study on the relationship between mass concentrations, chemistry and number size distribution of urban fine aerosols in Milan, Barcelona and London, Atmos. Chem. Phys., 7, 2217-2232, doi:10.5194/acp-72217-2007, 2007.
Seaton, A., Godden, D., MacNee, W., and Donaldson, K.: Particulate air pollution and acute health effects, Lancet, 345, 176-178, 1995.

Shi, J. P., Mark, D., and Harrison, R. M.: Characterization of particles from a current technology heavy-duty diesel engine, Environ. Sci. Technol., 34, 748-755, 2000.

Stanier, C. O., Khlystov, A. Y., and Pandis, S. N.: Nucleation events during the Pittsburgh air quality study: Description and relation to key meteorological, gas phase and aerosol parameters, Aerosol Sci. Technol., 38, 253-264, 2004.

Tunved, P., Ström, J., and Hansson, H.-C.: An investigation of processes controlling the evolution of the boundary layer aerosol size distribution properties at the Swedish background station, Aspvreten, Atmos. Chem. Phys., 4, 2581-2592, 2004, http://www.atmos-chem-phys.net/4/2581/2004/.

Williams, M. L. and Carslaw, D. C.: New Directions: Science and policy - Out of step on $\mathrm{NO}_{\mathrm{x}}$ and $\mathrm{NO}_{2}$ ?, Atmos. Environ., doi:10.1016/j.atmosenv.2011.04.067, 2011.

Wehner, B., Siebert, H., Stratmann, F., Tuch, T., Wiedensohler, A., Petäjä, T., Dal Maso, M., and Kulmala, M.: Horizontal homogeneity and vertical extent of new particle formation events, Tellus B, 59, 362-371, 2007.

Yue, D., Hu, M., Wu, Z., Wang, Z., Guo, S.,Wehner, B., Nowak, A., Achtert, P., Wiedensohler, A., Jung, J., Kim, Y. J., and Liu, S.: Characteristics of aerosol size distributions and new particle formation in the summer in Beijing, J. Geophys. Res., 114, D00G12, doi:10.1029/2008JD010894, 2009. 